\title{
Simulation of Wetting and Interfacial Behavior of Quaternary Ammonium and Phosphonium Ionic Liquid Nanodroplets Over Face-Centered Cubic Metal Surfaces
}

\author{
Maryam Bahrami, Mohammad Hadi Ghatee*, Seyyedeh Fatemeh Ayatollahi
}

(Department of Chemistry, Shiraz University, Shiraz 71946, Iran)

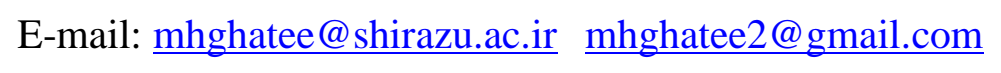

Fax: +98 7136460788, Tel: +98 7136137174 

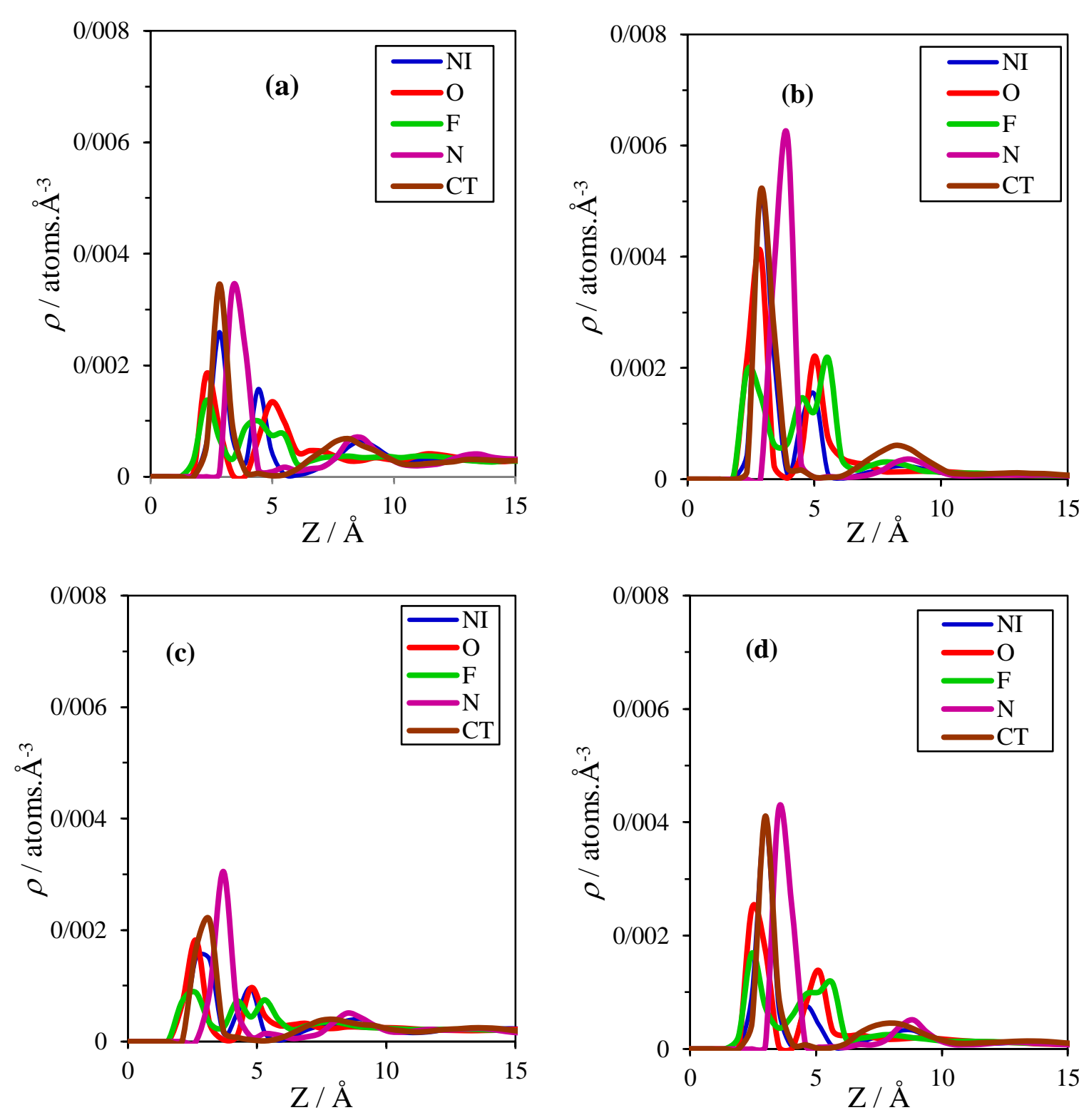

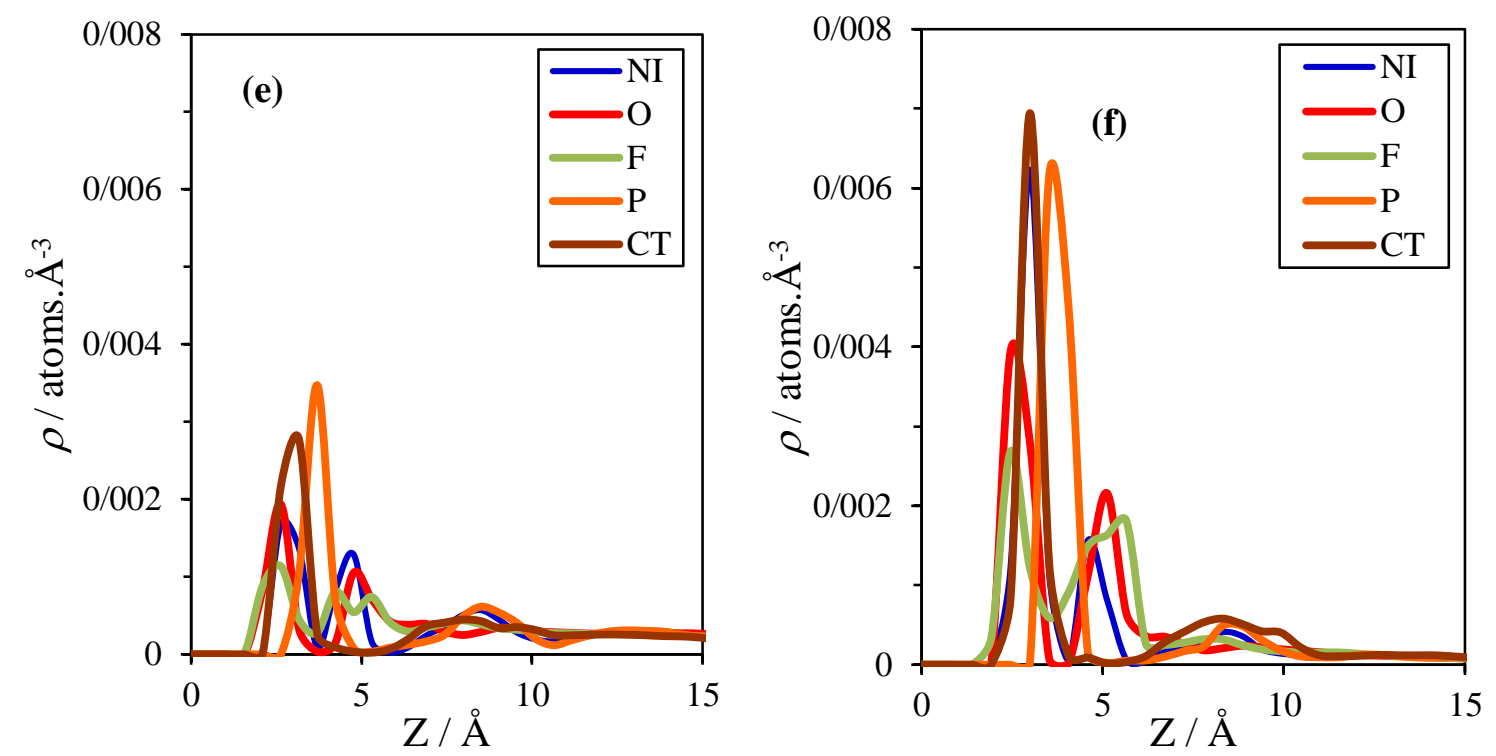

Figure S1. Atomic number density as a function of distance $\mathrm{z}$ from the metallic substrates for (a) $\left[\mathrm{N}_{2225}\right]\left[\mathrm{NTf}_{2}\right] / \mathrm{Cu}(100),\left(\right.$ b) $\left[\mathrm{N}_{2225}\right]\left[\mathrm{NTf}_{2}\right] / \mathrm{Cu}(111)$, (c) $\left[\mathrm{N}_{2225}\right]\left[\mathrm{NTf}_{2}\right] / \operatorname{Pt}(100),(\mathbf{d})\left[\mathrm{N}_{2225}\right]\left[\mathrm{NTf}_{2}\right] / \mathrm{Pt}(111),($ e) $\left[\mathrm{P}_{2225}\right]\left[\mathrm{NTf}_{2}\right] / \mathrm{Pt}(100)$ and (f) $\left[\mathrm{P}_{2225}\right]\left[\mathrm{NTf}_{2}\right] / \mathrm{Pt}(111)$.
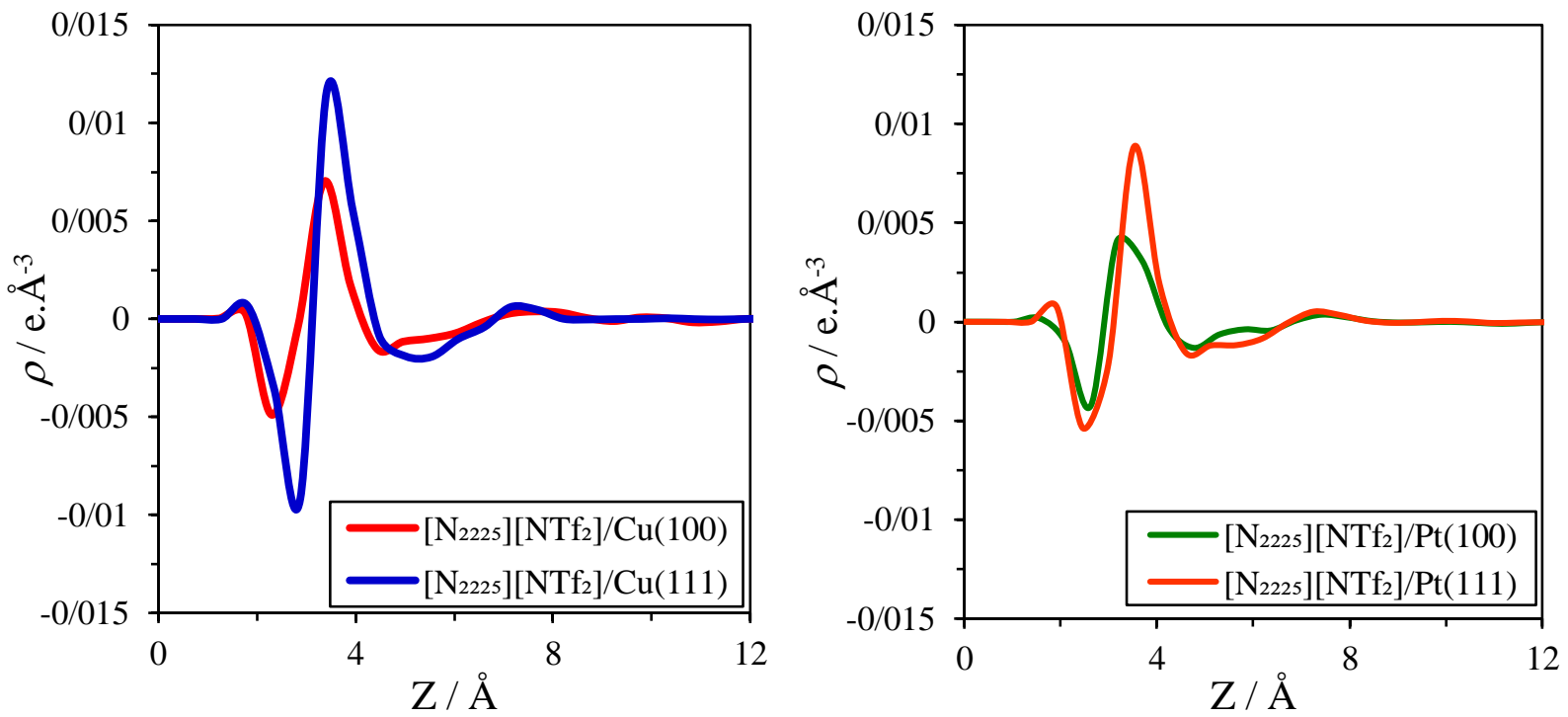


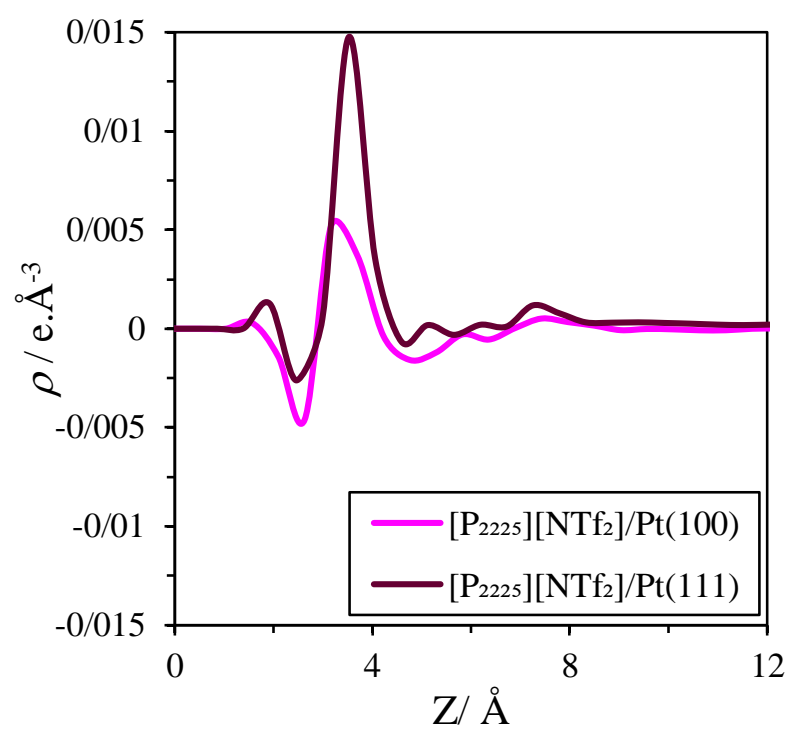

Figure S2. Total charge densities of $\left[\mathrm{N}_{2225}\right]\left[\mathrm{NTf}_{2}\right]$ and $\left[\mathrm{P}_{2225}\right]\left[\mathrm{NTf}_{2}\right]$ ILs nano-droplets as a function of zaxis of simulation box. Metal surfaces are at $\mathrm{z}=0$.

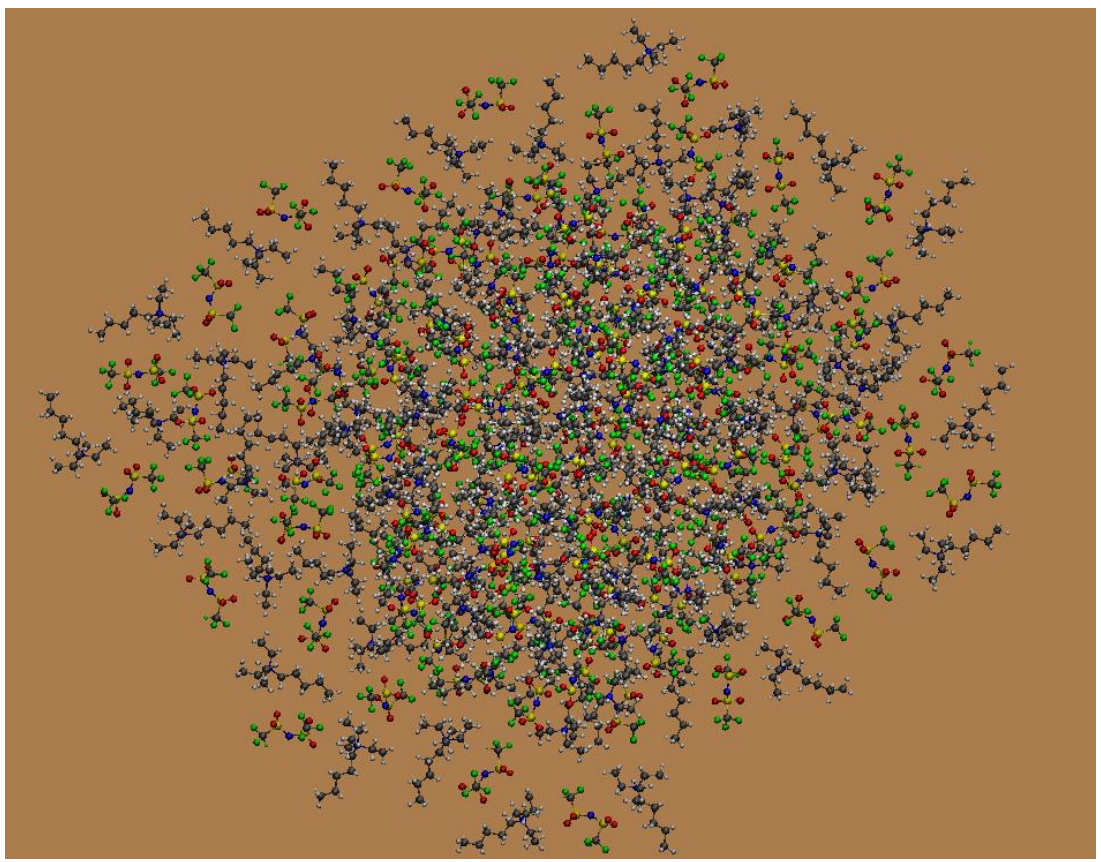

Figure S3. Top view of adsorbed $\left[\mathrm{N}_{2225}\right] \mathrm{NTf}_{2}$ IL nano-droplet on $\mathrm{Cu}(100)$ surface for the large system. 


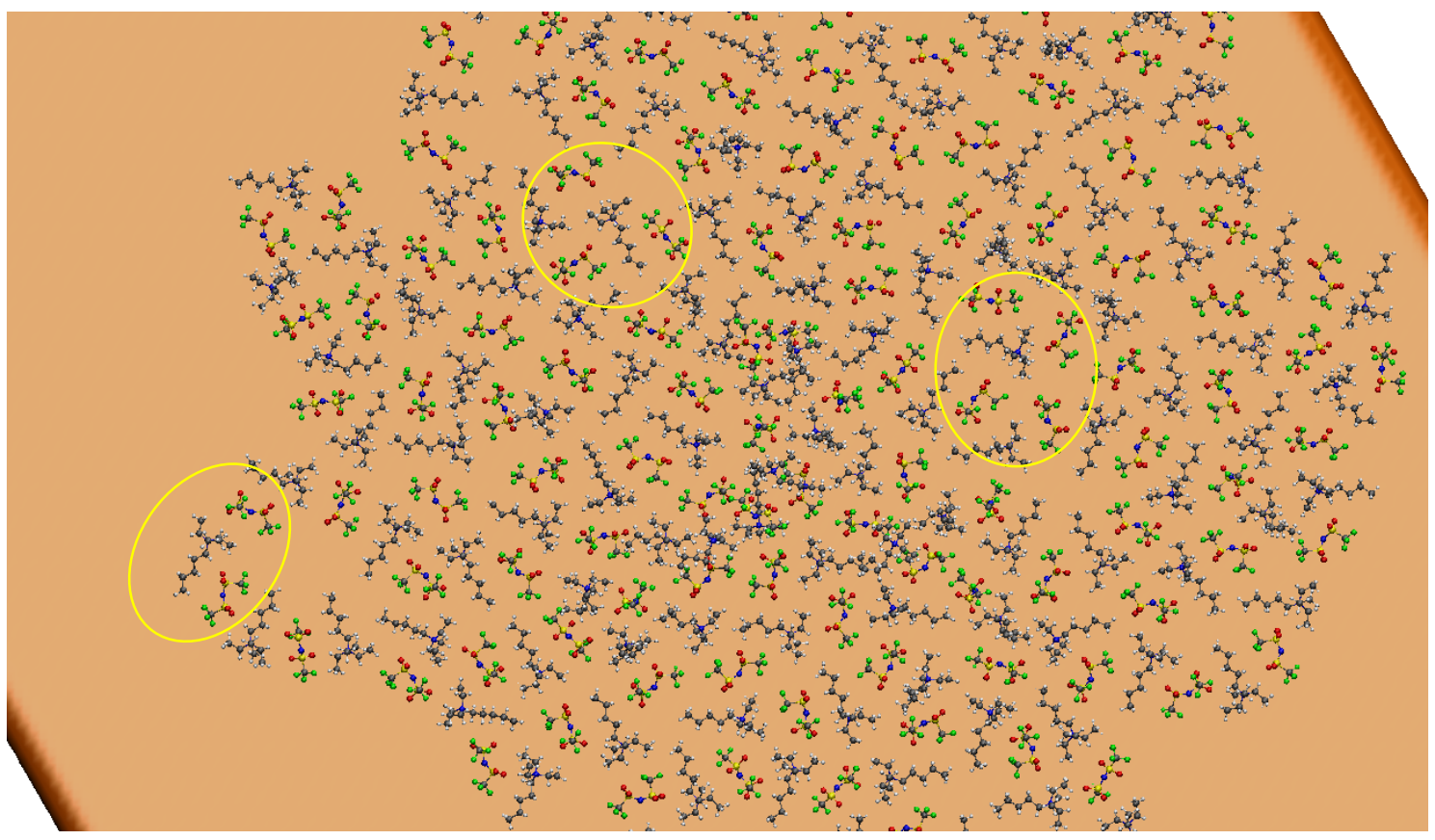

Figure S4. Top view of the first adsorbed layer of $\left[\mathrm{N}_{2225}\right] \mathrm{NTf}_{2}$ IL nano-droplet on $\mathrm{Cu}(111)$ surface for the large system. The circles highlight the possible anion-cation coordination.

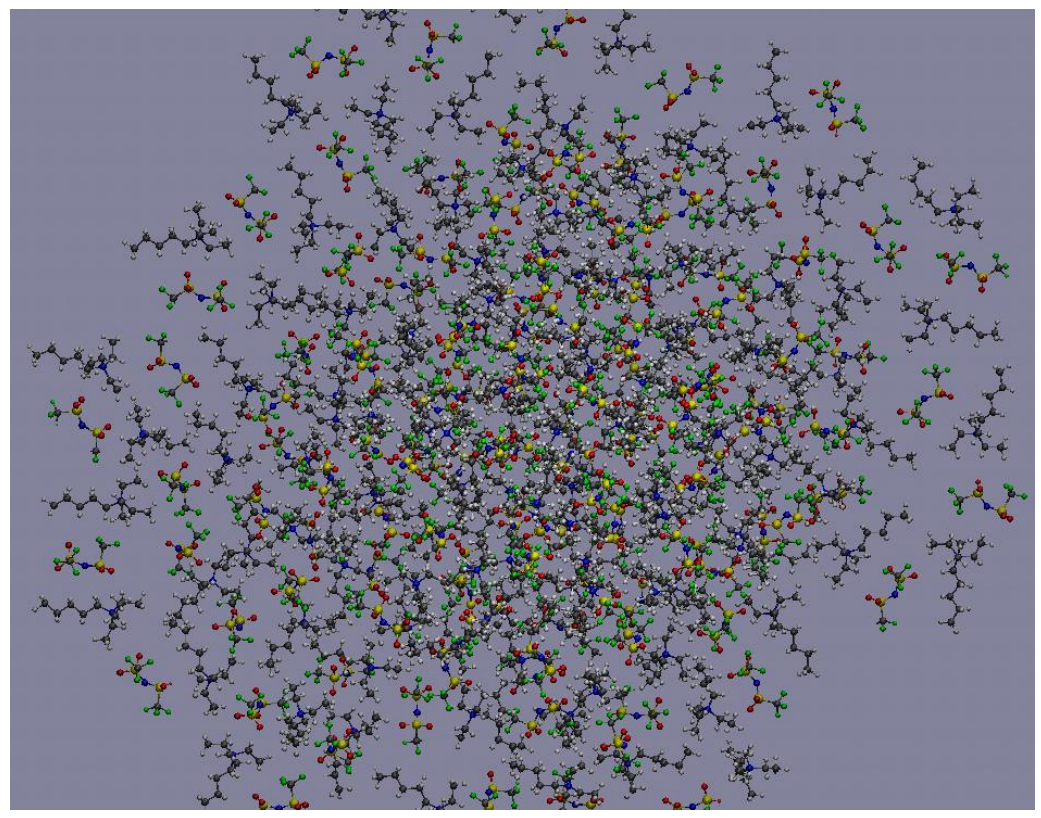

Figure S5. Top view of adsorbed $\left[\mathrm{N}_{2225}\right] \mathrm{NTf}_{2}$ IL nano-droplet on $\operatorname{Pt}(100)$ surface for the large system. 


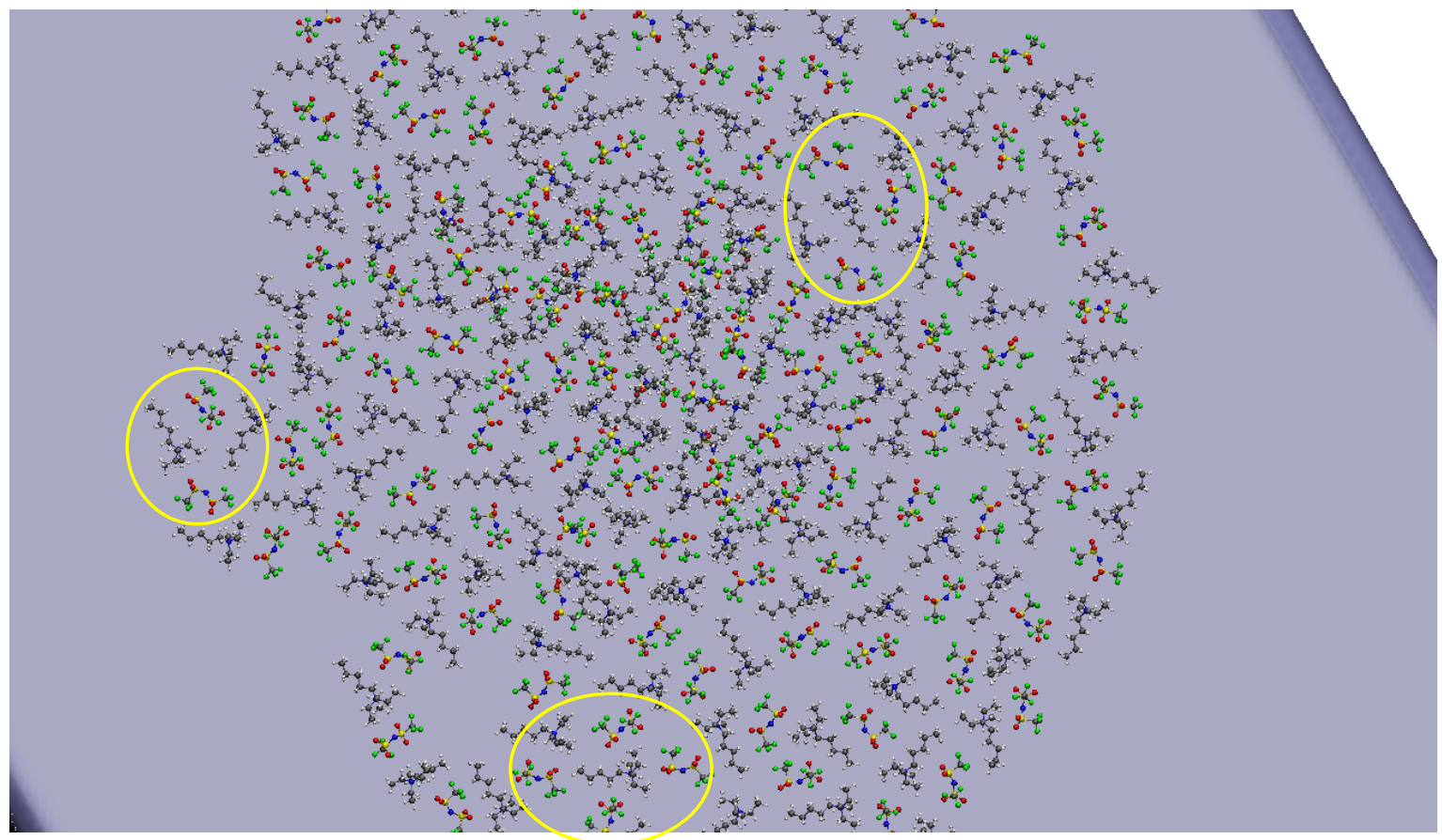

Figure S6. Top view of adsorbed $\left[\mathrm{N}_{2225}\right] \mathrm{NTf}_{2}$ IL nano-droplet on $\mathrm{Pt}(111)$ surface for the large system. Circle used to highlight the possible anion-cation coordination.

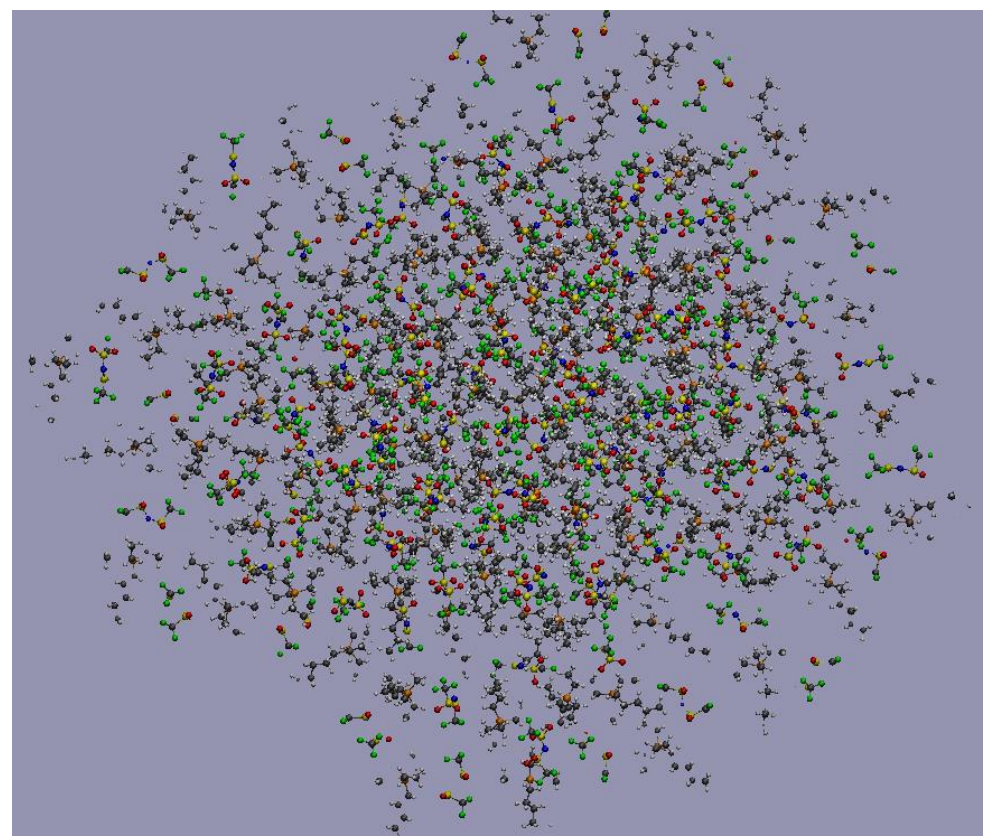

Figure S7. Top view of adsorbed $\left[\mathrm{P}_{2225}\right] \mathrm{NTf}_{2}$ IL nano-droplet on $\mathrm{Pt}(100)$ surface for the large system. 


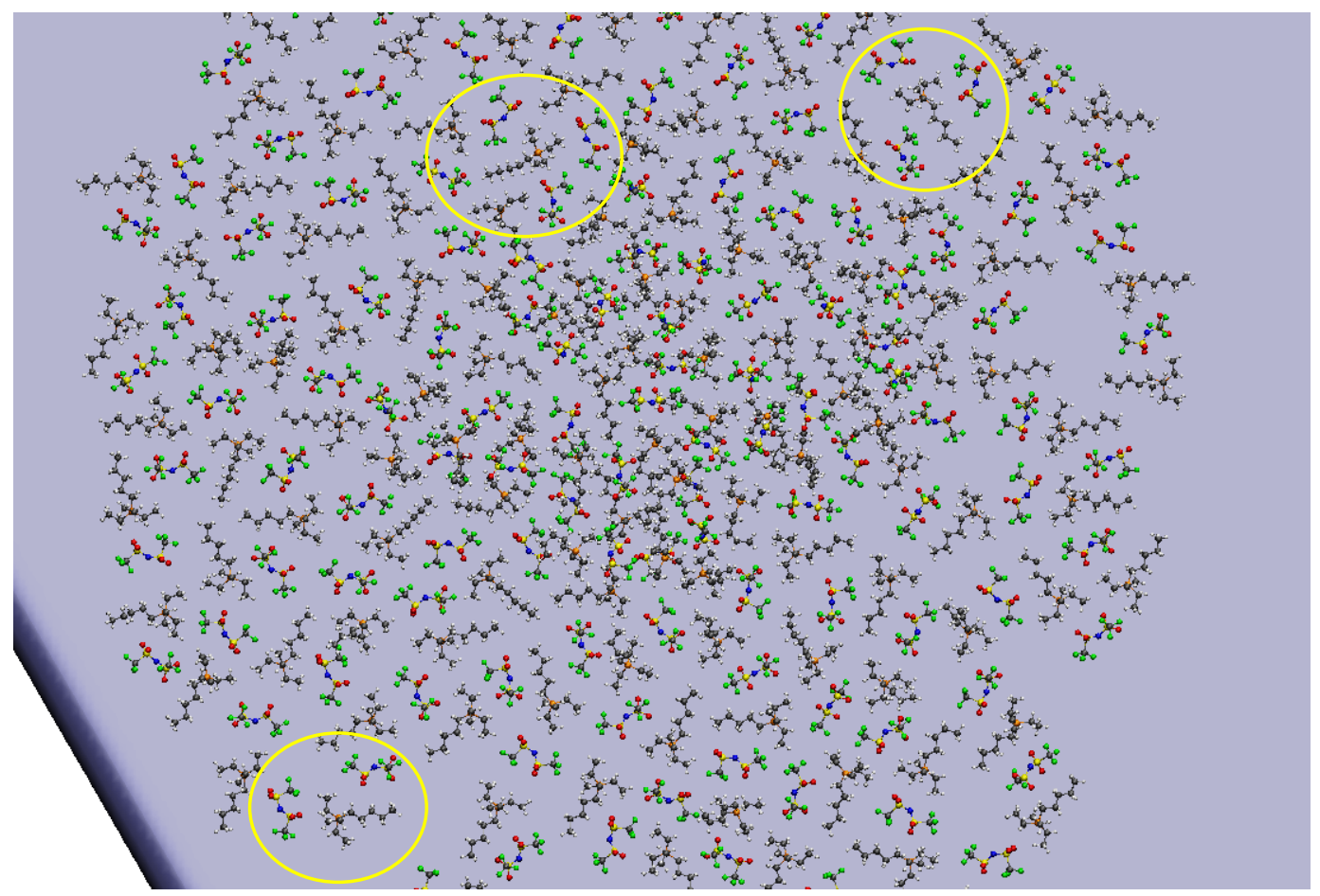

Figure S8. Top view of adsorbed $\left[\mathrm{P}_{2225}\right] \mathrm{NTf}_{2} \mathrm{IL}$ nano-droplet on $\mathrm{Pt}(111)$ surface for the large system. Circle used to highlight the possible anion-cation coordination.

Table S1. Neighbor count histogram of $\left[\mathrm{NTf}_{2}\right]$ anion around $\left[\mathrm{N}_{2225}\right]$ and $\left[\mathrm{P}_{2225}\right]$ cations on $\mathrm{Cu}(111)$ and $\mathrm{Pt}(111)$ surfaces. Only the major ones are shown.

\begin{tabular}{|l|c|c|}
\hline IL/Substrate system & Neighbor count & percent of the time \\
\hline & 2 & 20.29 \\
{$\left[\mathrm{~N}_{2225}\right]\left[\mathrm{NTf}_{2}\right] / \mathrm{Cu}(111)$} & 3 & 63.25 \\
& 4 & 13.33 \\
\hline$\left[\mathrm{N}_{2225}\right]\left[\mathrm{NTf}_{2}\right] / \mathrm{Pt}(111)$ & 2 & 19.37 \\
& 3 & 43.12 \\
\hline
\end{tabular}




\begin{tabular}{|c|c|c|}
\hline$\left[\mathrm{P}_{2225}\right]\left[\mathrm{NTf}_{2}\right] / \operatorname{Pt}(111)$ & 2 & 21.57 \\
& 3 & 41.08 \\
& 4 & 26.68 \\
\hline
\end{tabular}

